\title{
The contribution of the human medial temporal lobe to perception: Bridging the gap between animal and human studies
}

\author{
Andy C. H. Lee, Morgan D. Barense, and Kim S. Graham \\ MRC Cognition and Brain Sciences Unit, Cambridge, UK
}

\begin{abstract}
The medial temporal lobe (MTL) has been considered traditionally to subserve declarative memory processes only. Recent studies in nonhuman primates suggest, however, that the MTL may also be critical to higher order perceptual processes, with the hippocampus and perirhinal cortex being involved in scene and object perception, respectively. The current article reviews the human neuropsychological literature to determine whether there is any evidence to suggest that these same views may apply to the human MTL. Although the majority of existing studies report intact perception following MTL damage in human amnesics, there have been recent studies that suggest that when scene and object perception are assessed systematically, significant impairments in perception become apparent. These findings have important implications for current mnemonic theories of human MTL function and our understanding of human amnesia as a result of MTL lesions.
\end{abstract}

Large lesions to the medial temporal lobes (MTL), including the hippocampus proper, subiculum, parahippocampal cortex, enthorinal cortex, and perirhinal cortex, are known to produce severe long-term memory impairments in both nonhuman primates (Alvarez, Zola-Morgan, \& Squire, 1994; Gaffan, Parker, \& Easton, 2001; Mishkin, 1982) and humans (Scoville \& Milner, 1957). On the basis of these observations, it has been proposed that the primate MTL structures function as a single memory system important for the acquisition of new facts and events (termed declarative memory), with the degree of memory deficit correlating positively with the extent of MTL damage (Squire \& Zola-Morgan, 1991; Zola-Morgan, Squire, \& Ramus, 1994). A modification of this theory is that the different MTL areas subserve distinct mnemonic processes: for example, with the hippocampus mediating the recollection of episodic and contextual information, particularly in the

Correspondence should be addressed to Dr Andy Lee, MRC Cognition and Brain Sciences Unit, 15 Chaucer Road, Cambridge CB2 2EF, UK. Email: andy.lee@mrc-cbu.cam.ac.uk

The authors would like to thank Drs M. Buckley, T. Bussey, D. Gaffan, E. Murray, and L. Saksida for feedback on this and related work. The authors are funded by the Alzheimer's Research Trust, UK, and the Medical Research Council, UK.

(C) 2005 The Experimental Psychology Society

http:/ /www.tandf.co.uk/journals/pp/02724995.html

DOI:10.1080/02724990444000168 
domain of space, and the perirhinal cortex playing a unique role in object memory and recognition memory based on familiarity (Aggleton \& Brown, 1999; Brown \& Aggleton, 2001; Mishkin, Suzuki, Gadian, \& Vargha-Khadem, 1997). According to this account, the profile of memory impairment following MTL lesions will depend on the exact location of any damage.

A more recent and controversial suggestion, which has risen primarily from the animal literature, is that the primate MTL may not mediate declarative memory processes exclusively but may, in fact, be involved in higher order perceptual processes (e.g., formation of visual representations; Buckley, Booth, Rolls, \& Gaffan, 2001; Bussey, Saksida, \& Murray, 2002; Murray \& Bussey, 1999). The majority of evidence for this view comes from studies that have examined the role of the perirhinal cortex in monkeys in object perception and have found that lesions to this structure can result in severe object discrimination deficits (see Buckley, this issue; Bussey, Saksida, \& Murray, this issue, full discussion). In brief, it has been proposed that the ventral "what" visual processing stream may culminate in the perirhinal cortex (Murray \& Bussey, 1999). Thus, while simple features (e.g., colour, size) may be represented in more caudal visual regions such as V4 and TE/TEO, more complex conjunctions of features (e.g., objects) may be represented in rostral regions including the perirhinal cortex.

A nonmnemonic role in spatial perception has also been proposed for the hippocampus (Gaffan, 2001; Horel, 1978; O'Keefe, 1999). While there has been, to date, no direct experimental evidence to support this hypothesis, a large body of existing animal hippocampal data appear to be consistent with a role for the hippocampus in processing spatial information. For instance, nonhuman primate lesion studies have demonstrated that the hippocampus is essential for tasks on which performance is dependent upon spatial memory (Buckley, Charles, Browning, \& Gaffan, 2004; Hampton, Hampstead, \& Murray, 2004; Murray, Davidson, Gaffan, Olton, \& Suomi, 1989), and, furthermore, there is an abundance of evidence that animals (Hori et al., 2003; O'Keefe, 1976; O'Keefe \& Burgess, 1996; O’Keefe, Burgess, Donnett, Jeffery, \& Maguire, 1998; Ono, Nakamura, Fukuda, \& Tamura, 1991; Ono, Nakamura, Nishijo, \& Eifuku, 1993; Wilson \& McNaughton, 1993) possess hippocampal place cells that may signal aspects of spatial location and navigation.

One extension to a perceptual view of the primate MTL is that the severe declarative memory impairments that often result from lesions to MTL structures may be explained, at least in part, by a primary deficit in higher order perception (Gaffan, 2001; Horel, 1978): for instance, difficulties with object perception following perirhinal cortex damage or an impairment in spatial perception after lesions to the hippocampus. If true, then perceptual theories of MTL function will have a profound impact on our current understanding of the functional organization of declarative memory in the brain, as well as profiles of amnesia in animals and humans following MTL damage.

The aim of the current review, therefore, is to explore whether there is any evidence for the human MTL subserving the same perceptual processes that have been proposed for the perirhinal cortex and hippocampus in animals. Given that functional neuroimaging studies of MTL function have already been discussed in detail elsewhere (see Henson, this issue) this paper concentrates primarily on the patient neuropsychological literature. Furthermore, due to the large volume of studies that have been conducted on MTL function, discussion is restricted primarily to patients with static focal lesions, as opposed to cases with 
progressive diseases that impact the MTL (e.g., Alzheimer's Disease). As a starting point, a brief overview of existing studies of mnemonic function in amnesic patients with MTL damage is provided, in particular focusing on those investigations that have assessed perceptual function alongside memory performance. This shows that, to date, there has been little evidence for the human MTL subserving perceptual processing (although this has not been tested systematically) and that, as a result, the existing literature supports the general conclusion that the human MTL mediates declarative memory processes exclusively.

Following this, a more detailed discussion is carried out on a handful of recent neuropsychological studies that were specifically conducted to investigate the perceptual abilities of amnesic patients (Buffalo, Reber, \& Squire, 1998; Holdstock, Gutnikov, Gaffan, \& Mayes, 2000a; Lee et al., 2005a; Lee et al., 2005c; Stark \& Squire, 2000). In contradiction with the existing literature, two of these studies have demonstrated that MTL damage in humans can lead to perceptual deficits (Lee et al., 2005a; Lee et al., 2005c). The implications of these new findings are considered, in terms of (a) how they may be reconciled with studies that have failed to support a role for MTL structures in perception (Buffalo et al., 1998; Holdstock et al., 2000a; Stark \& Squire, 2000) and (b) how deficits in perception may interact with declarative memory function and underlie aspects of the human amnesic syndrome. With respect to the latter, specific mention is made of a recent study that has examined the impact that deficits in object perception may have on a form of declarative learning (Barense et al., 2005). This review then finishes by considering how more recent perceptual theories of MTL function may be reconciled with existing mnemonic theories of the human MTL, and possible avenues of further research are discussed.

\section{A role for the human MTL in memory only?}

\section{Existing studies of mnemonic function and the human MTL}

Since the initial description of severe amnesia in patient H.M. and other patients with large bilateral lesions to the MTL (Scoville \& Milner, 1957), there have been a myriad of studies that have investigated various aspects of mnemonic functioning and profiles of retrograde and anterograde memory loss following damage to MTL structures (for a recent review, see Spiers, Maguire, \& Burgess, 2001a). These include investigations into new semantic memory learning (e.g., Bayley \& Squire, 2004; Gadian et al., 2000; Manns, Hopkins, \& Squire, 2003b; Vargha-Khadem et al., 1997), differences in recollection versus familiarity-based recognition (e.g., Holdstock et al., 2002; Manns, Hopkins, Reed, Kitchener, \& Squire, 2003a; Mayes, Holdstock, Isaac, Hunkin, \& Roberts, 2002; Mayes et al., 2004; Yonelinas et al., 2002), working memory (e.g., Cave \& Squire, 1992b; Fujii, Yamadori, Endo, Suzuki, \& Fukatsu, 1999), and different facets of nondeclarative memory: for instance, priming (e.g., Cave \& Squire, 1992a; Levy, Stark, \& Squire, 2004; Musen \& Squire, 1992; Postle \& Corkin, 1998), perceptual learning (e.g., Kartsounis, Rudge, \& Stevens, 1995; Manns \& Squire, 2001), and motor learning (e.g., Gabrieli, Corkin, Mickel, \& Growdon, 1993; Muramoto, Kuru, Sugishita, \& Toyokura, 1979). Although a detailed discussion of the findings of these studies is beyond the scope and aims of the present review (for full review see Spiers, Maguire, \& Burgess, 2001a; Squire, Stark, \& Clark, 2004), there are a couple of observations that can be made with respect to the MTL and mnemonic function. First, 
there is an abundance of evidence to suggest that the MTL is essential for long-term declarative memory, but often not for nondeclarative memory (e.g., Cave \& Squire, 1992a; Kartsounis et al., 1995; Levy et al., 2004; Manns \& Squire, 2001; Musen \& Squire, 1992; but see Chun \& Phelps, 1999) or working memory (e.g., Cave \& Squire, 1992b; Rempel-Clower, Zola, Squire, \& Amaral, 1996). Second, as mentioned in the Introduction, the data on functional fractionation within the MTL are less clear, with some reports arguing for functional specialization within different MTL structures (Aggleton \& Brown, 1999; Brown \& Aggleton, 2001; Mishkin et al., 1997) and others concluding that all MTL structures function in concert as a unitary declarative memory system (Squire, 2004; Squire et al., 2004; Squire \& Zola-Morgan, 1991; Zola-Morgan et al., 1994).

In favour of a single memory system, there have been numerous studies showing that selective lesions to the human hippocampus can result in mnemonic deficits across multiple domains of declarative memory function, including impaired acquisition of new semantic memory and deficits in episodic memory retrieval on the basis of both recollection and familiarity (e.g., Bayley \& Squire, 2004; Gabrieli, Cohen, \& Corkin, 1988; Manns et al., 2003a; Manns et al., 2003b; for review see Squire et al., 2004). Contradictory evidence, however, comes from studies that have shown that circumscribed hippocampal damage does leave some memory functions intact. For example, in contrast to those studies that support a unitary view, Vargha-Khadem et al. (1997) and Gadian et al. (2000) found that the hippocampal formation is not essential for acquiring new semantic information in developmental amnesic cases. Furthermore, there have been a number of studies that have found preservation of object recognition memory in hippocampal lesion patients (Baddeley, Vargha-Khadem, \& Mishkin, 2001; Holdstock et al., 2002; Mayes et al., 2002; Yonelinas et al., 2002).

In addition to the above, there is also a considerable collection of neuropsychological data indicating that the human hippocampus, as well as the parahippocampal gyrus, may have a significant role in spatial memory and navigation. Patients with hippocampal and/or parahippocampal damage are known to be significantly impaired in spatial memory and navigation (Bohbot, Iaria, \& Petrides, 2004; Bohbot et al., 1998; Burgess, Maguire, \& O'Keefe, 2002; Feigenbaum \& Morris, 2004; Holdstock et al., 2000b; King, Burgess, Hartley, Vargha-Khadem, \& O'Keefe, 2002; King, Trinkler, Hartley, Vargha-Khadem, \& Burgess, 2004; Spiers, Burgess, Hartley, Vargha-Khadem, \& O’Keefe, 2001b). Additionally, there is now evidence that there are cells within the human MTL, analogous to those found in the rat and monkey hippocampus, that signal aspects of space processing, with cells sensitive to location in the hippocampus and cells sensitive to views of landmarks in the parahippocampal gyrus (Ekstrom et al., 2003).

There are currently two main contrasting theories that attempt to make sense of these data. In brief, one line of thought posits that the hippocampus in animals and humans operates as a spatial module or cognitive map (O'Keefe \& Nadel, 1978), with additional involvement in temporal information processing and linguistic processes critical for the formation of episodic memory in humans (O'Keefe, 1999; O'Keefe \& Burgess, 1996). In contrast, it has been proposed that the hippocampus is involved in "relational" memorythat is, memory for relationships among perceptually distinct items (Cohen et al., 1999; Eichenbaum \& Cohen, 2002; Eichenbaum, Otto, \& Cohen, 1994). Thus, according to this view, the hippocampus is not specialized for spatial processing per se but, rather, 
plays a broader role in processing a wide range of relational associations, including spatial relations.

\section{Existing studies of perceptual function and the human MTL}

If the human MTL does subserve nonmnemonic perceptual processes, as suggested by recent data in the animal literature (see Buckley, this issue; Bussey et al., this issue), then one would expect there to have been some support for this view from the wealth of neuropsychological studies that have investigated the effects of human MTL damage on cognitive function over the past 50 years. This, however, does not appear to be the case. First, the fact that patients with MTL damage generally show normal motor and perceptual learning has been taken as evidence that perception is intact in these patients (e.g., Gage, 1985; Iverson, 1977). For example, amnesic cases can demonstrate an improvement in performance accuracy and response times if they are required to do certain tasks repeatedly (e.g., mirror drawing, visual search), even in the absence of any explicit memory for previous experiences (e.g., Gabrieli et al., 1993; Manns \& Squire, 2001; Muramoto et al., 1979; but see Chun \& Phelps, 1999). Second, there has been little evidence from studies of perceptual function that damage to the human MTL alone can lead to perceptual difficulties.

Notably, however, a brief review of the existing literature reveals that only a proportion of studies has assessed perceptual abilities along with performance on memory tasks. Table 1 (pp. 306-309) lists these studies, giving details of the patients involved (e.g., location and extent of their cortical damage), which perceptual assessments were carried out, and, lastly, the patients' performance on these tests. Although a few of these studies assessed visual perception by using experimental tasks that placed a low demand on mnemonic processes-for example tasks of visual matching (Buffalo et al., 1998; Holdstock et al., 2000a; Squire, 1993) - more commonly standardized neuropsychological tests of perception were utilized. These include the copying condition of the Rey-Osterrieth figure (Osterrieth, 1944), which requires subjects to make a copy of a complex drawing using pen and paper, and the Visual Object Space Perception (VOSP; Warrington \& James, 1991) battery (Table 1), which is composed of a series of tests that assess a variety of perceptual abilities, including identifying incomplete pictures of letters, noting the positions and quantities of items on a page, and analysing three-dimensional line drawings of blocks composed of cubes. Due to space limitations, studies that have included patients with amnesia due to fornix transection have been omitted. Moreover, only those studies that have used perceptual tasks that do not contain a memory component (e.g., semantic/episodic) have been included. For example, while the Gollin incomplete figures test (Gollin, 1960) and the object silhouette task of the VOSP (Warrington \& James, 1991) assess the ability to perceive common objects from incomplete drawings and silhouettes, respectively, they both require semantic knowledge of these objects.

The overall consensus from the studies listed in Table 1 is that patients with MTL damage usually perform within the normal range on tasks of perception. Interestingly, however, there have been isolated cases where MTL patients have demonstrated impaired performance on tasks that do not appear to be mnemonic in nature. For instance, while patient HM was able to accurately perceive facial features and cartoon drawings, he was, however, impaired on a version of Gottschaldt's (Gottschaldt, 1929) hidden figure task, in which geometric patterns have to be identified and traced out within a network of embedding and 
overlapping lines (Milner, Corkin, \& Teuber, 1968). In addition to this, a number of studies have found MTL lesion patients to be impaired on standard neuropsychological tasks, such as the Rey-Osterrieth figure copy condition (e.g., Benson, Marsden, \& Meadows, 1974; Woods, Schoene, \& Kneisley, 1982). Importantly, however, these deficits have often not been attributed to damage to the MTL, but rather to cortical damage beyond this region, in particular to occipital and more posterior lateral temporal lobe regions (e.g., Benson et al., 1974). In keeping with this, there have been, to our knowledge, no previous reports of perceptual deficits in patients who have cortical damage that is restricted to MTL structures bilaterally (see Table 1).

Two recent studies that specifically attempted to investigate a possible role for the perirhinal cortex in object perception are Buffalo et al. (1998) and Holdstock et al. (2000a). In brief, both of these investigations employed variations of a matching to sample (MTS) paradigm to assess a range of amnesic patients, including those with focal damage encompassing the perirhinal cortex bilaterally. In Buffalo et al. (1998), the participants were presented with four successive multicoloured complex visual designs, each for $1 \mathrm{~s}$ and with a $1 \mathrm{~s}$ interstimulus interval per trial. Following delays of 0 to $40 \mathrm{~s}$, the participants were presented with a single test image and were required to decide whether this stimulus was one of the designs that had been shown previously. Similarly, Holdstock et al. (2000a) presented participants with a single monochromatic abstract pattern for $2.5 \mathrm{~s}$ per trial. In a simultaneous MTS condition, this pattern remained on the screen with 14 possible targets, and the subjects were instructed to match the two identical stimuli. In contrast, in the delayed MTS conditions, the target item was removed from the screen, and after delays of 0 to $30 \mathrm{~s}$, the participants were required to select the pattern that they had seen earlier from 14 possible choices.

In the aforementioned studies, it was found that amnesic patients with perirhinal cortex damage were not impaired on MTS of abstract visual stimuli when there was an absent or minimal memory demand (e.g., simultaneous to 5-s MTS in Holdstock et al., 2000a; 0-2 s MTS in Buffalo et al., 1998). Significant deficits in performance were, however, evident when the delay was increased between stimulus presentation and recognition $(10 \mathrm{~s}$ and above in Holdstock et al., 2000a; $6 \mathrm{~s}$ and above in Buffalo et al., 1998), suggesting that these patients suffered from recognition memory, but not perceptual, difficulties. On the basis of these findings, both Buffalo et al. (1998) and Holdstock et al. (2000a; this issue) concluded that the human perirhinal cortex does not appear to be critical for visual perception, and that this MTL region may subserve long-term mnemonic processes, especially recognition memory for objects, exclusively.

While the absence of a perceptual deficit following human MTL damage is contrary to recent reports from the animal literature (Buckley et al., 2001; Bussey et al., 2002; Bussey, Saksida, \& Murray, 2003; Eacott, Gaffan, \& Murray, 1994), it is possible that this discrepancy may be explained by considering the stimuli that were employed by Buffalo et al. (1998) and Holdstock et al. (2000a). For example, in these experiments two-dimensional abstract patterns, composed of varying shapes, colours, and lines, were used, with few overlapping features (or stimulus components) across the different stimuli. It is possible, therefore, to argue that these stimuli did not place a large demand on the types of perceptual process that have been attributed to the perirhinal cortex in monkeys (e.g., perception of conjunctions of object features; Buckley et al., 2001; Bussey \& Saksida, 2002; Bussey et al., 2002; Bussey et al., 2003; Eacott et al., 1994; Murray \& Bussey, 1999) and that the patients in these studies 


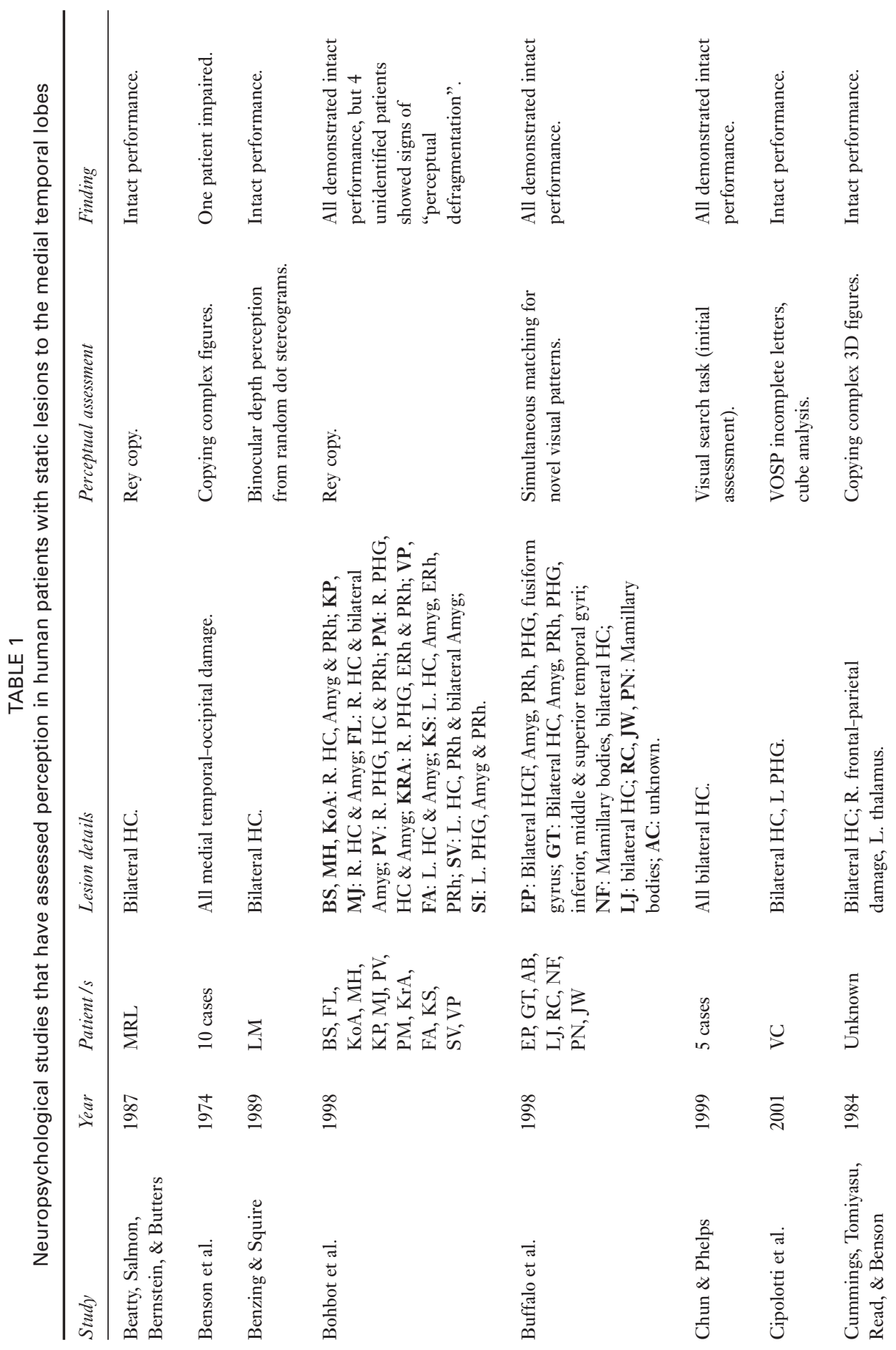



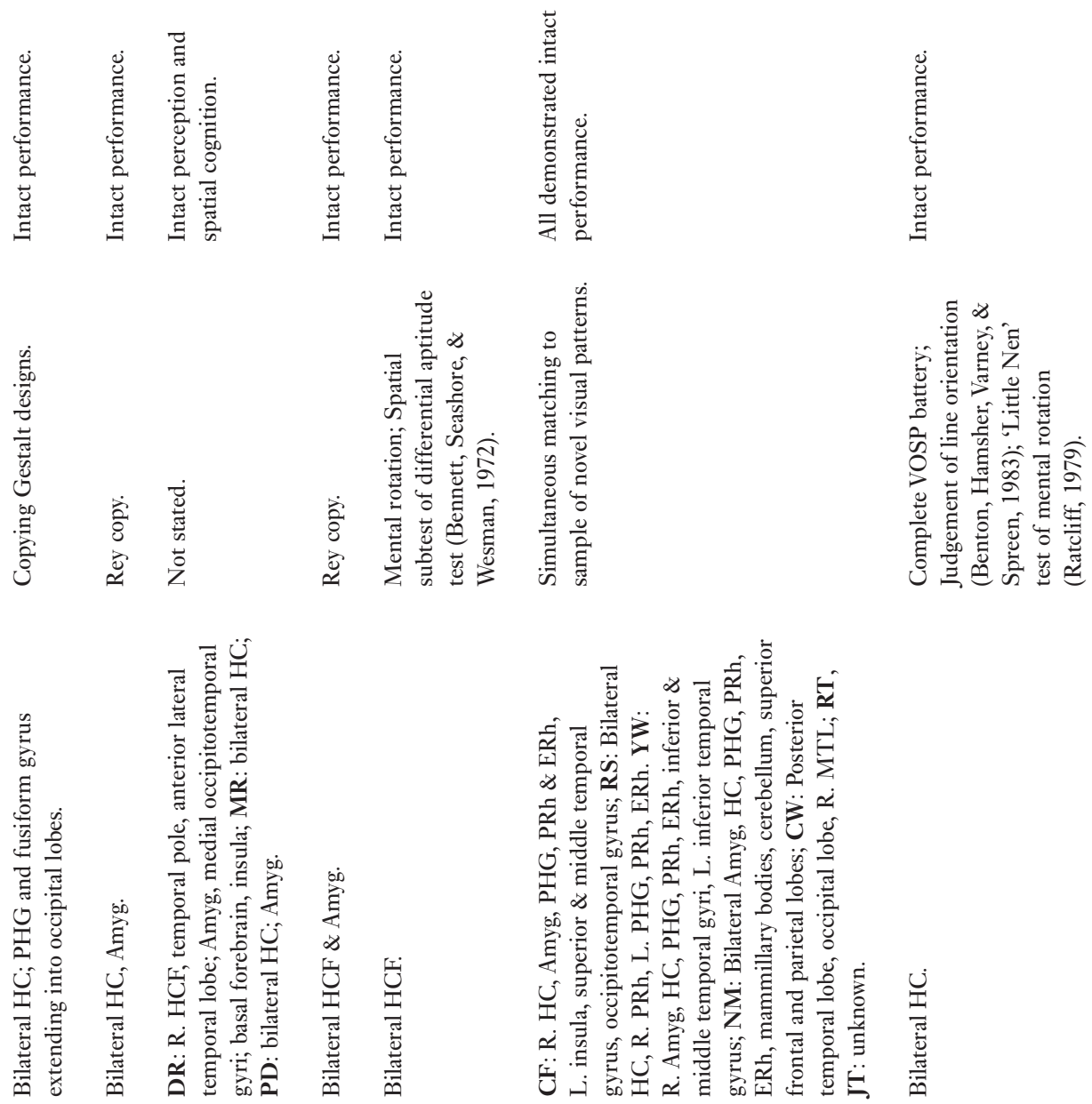

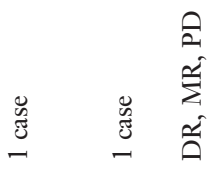

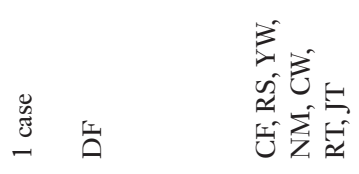

政

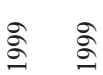

옹

$\approx$

ڤิ

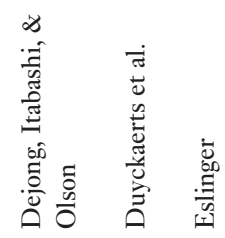

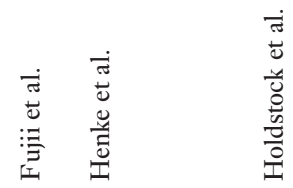

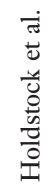




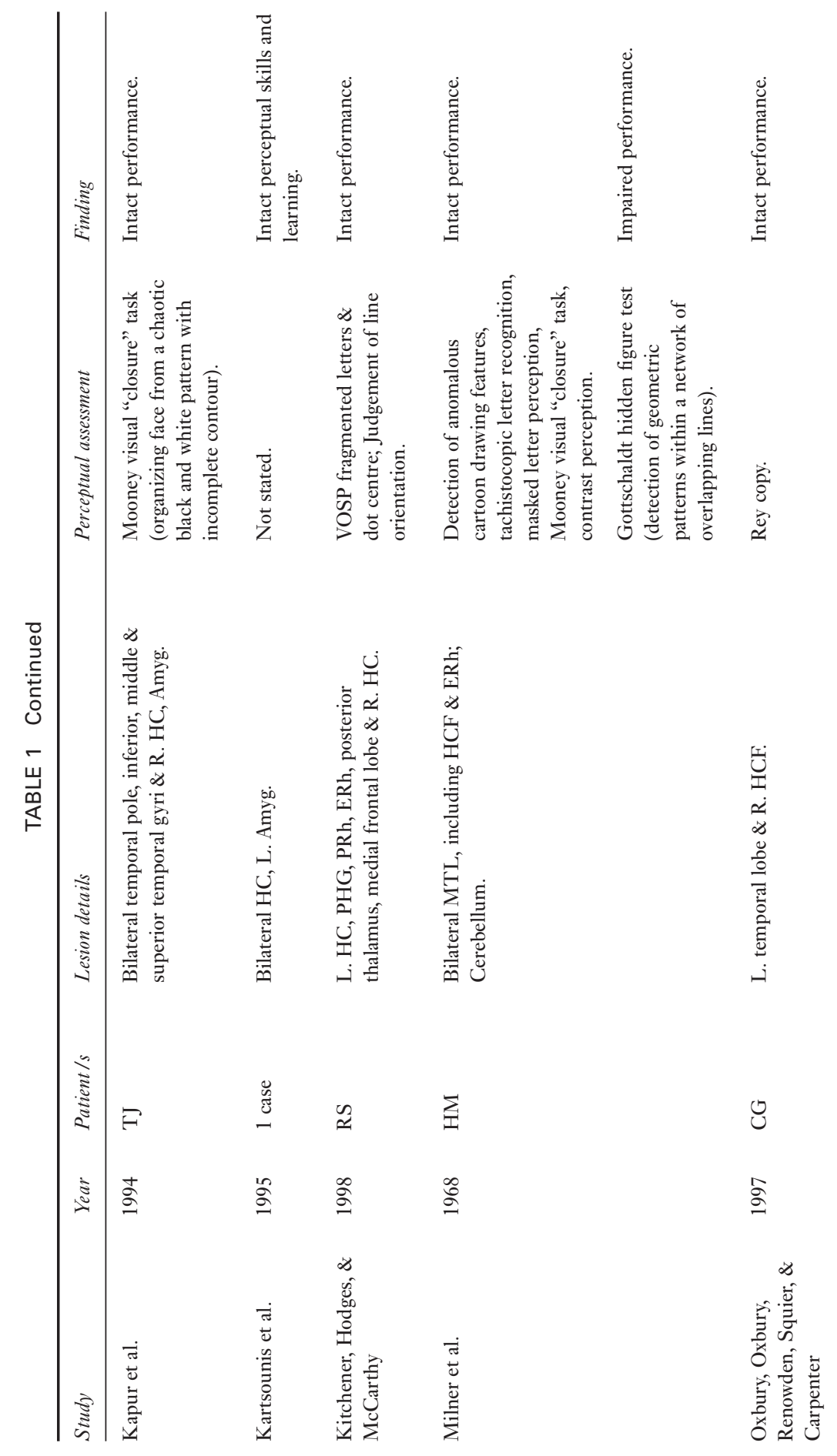


竞竞

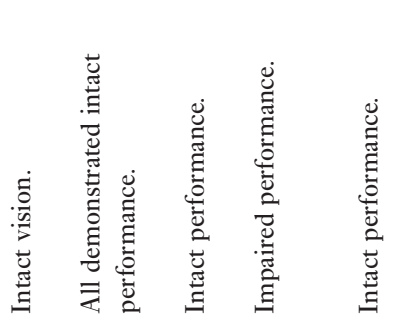

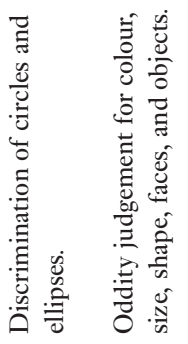

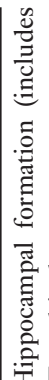

结圆

毞

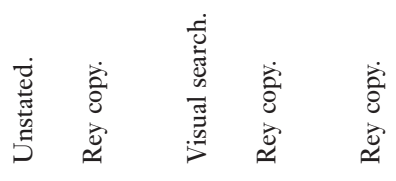

我

은

害苋

离

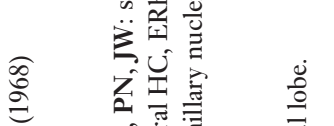

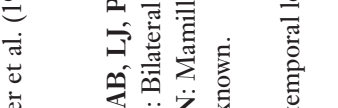

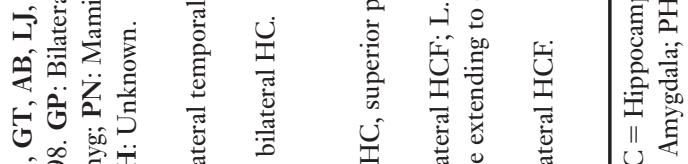

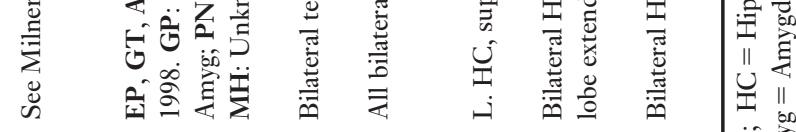

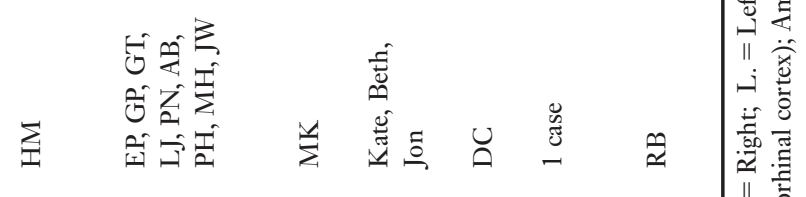

怘

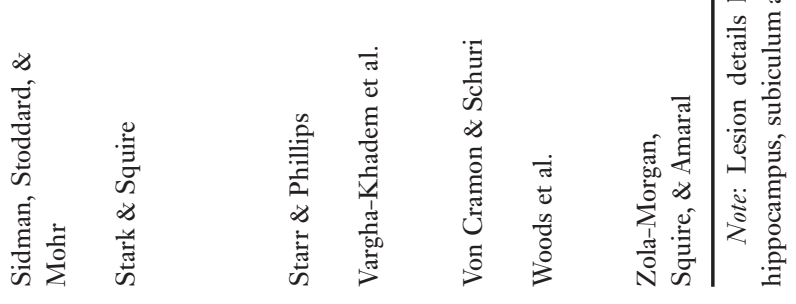


solved the tasks primarily on the basis of single-feature discrimination (which is not thought to be dependent upon perirhinal cortex). A similar argument may be applied to existing standardized neuropsychological tests of perception (Rey-Osterrieth figure copy, VOSP battery), in that none of these tasks adequately assess the ability to discriminate conjunctions of features. Consequently, it may not be surprising that, to date, there has been no convincing evidence that lesions to the human MTL can result in perceptual difficulties.

This issue was addressed in a study by Stark and Squire (2000), in which the ability of amnesic patients to discriminate visual stimuli was assessed using an adaptation of a nonmnemonic oddity judgement task that had been previously utilized in monkeys with perirhinal cortex lesions (Buckley et al., 2001). In this paradigm, the participants were required to select the odd stimulus from an array of six images taken from a variety of stimulus categories. While some of these discriminations could be made on the basis of single features (e.g., oddity judgement for shape, colour, and size), other discriminations placed a greater demand on perceiving conjunctions of features (e.g., oddity judgement for objects, masked with varying degrees of visual noise, and faces). In the original monkey study, Buckley et al. (2001) found that simple single-feature discriminations were not dependent on the perirhinal cortex, while judgements for objects and faces were impaired following selective perirhinal cortex damage. Contrary to these observations, however, Stark and Squire (2000) found that their amnesic patients with perirhinal cortex damage performed within the normal range across all stimulus conditions, even on those that were sensitive to perirhinal cortex damage in monkeys. Given that this difference could not be attributed to a lack of difficulty in the tasks used (both patients and healthy controls performed around the $60 \%$ mark in the hardest oddity conditions), it was concluded that the human perirhinal cortex is "functionally different from the perirhinal cortex in monkeys with respect to visual perception" (Stark $\&$ Squire, 2000) and that this region must serve mnemonic processes exclusively.

\section{New evidence for a role of the human MTL in perception}

\section{Deficits in visual discrimination following human MTL damage}

Although recent studies have investigated the role of the human perirhinal cortex in perception, no studies have, to our knowledge, examined a possible role for the human hippocampus in spatial perception as suggested recently in the animal literature (e.g., Gaffan, 2001). In order to address this issue and also to replicate and extend the findings of Stark and Squire (2000), we recently assessed fine visual discrimination in amnesic patients with either selective hippocampal damage (HC group) or more extensive medial temporal damage including the perirhinal cortex (MTL group). Importantly, both patient groups were tested initially on general neuropsychological tasks of perception, including the complete VOSP battery (Warrington \& James, 1991), the Rey-Osterrieth figure copy condition (Osterrieth, 1944), and the Benton face task (Benton \& Van Allen, 1968). It was found, in agreement with the existing literature, that all patients performed within the normal range on these tests, suggesting intact perceptual abilities as they are traditionally assessed.

With respect to the experimental tasks, different conditions of two simple computerized visual discrimination tasks were administered (Lee et al., 2005c). In brief, the two 
discrimination tasks were both based on the same experimental paradigm, but whereas successful performance on one task was dependent on the participants learning a single visual image (discrimination performance task), the second test placed a minimal demand on mnemonic processing (simultaneous matching task). On the first three trials of each condition in the discrimination performance task (see Figure 1), a pair of unfamiliar images from one of four stimulus categories (faces, objects, spatial scenes, or colour) was presented on a touchscreen monitor, and the participants were instructed to identify the "correct" picture by touching it. Selecting the correct stimulus produced a high tone, while the incorrect image was associated with a low tone. From Trials $4-53$, the same pictures were then blended together to create 50 new trial-unique pairs with five different levels of overlapping features: $0-9 \%, 10-19 \%, 20-29 \%, 30-39 \%$, and $40-49 \%$ of shared features. There were 10 trials for each level of blending, and these were pseudorandomly ordered such that 2 trials from each level were presented during each block of 10 trials. The participants were asked to select the image that they perceived to contain a greater proportion of the original
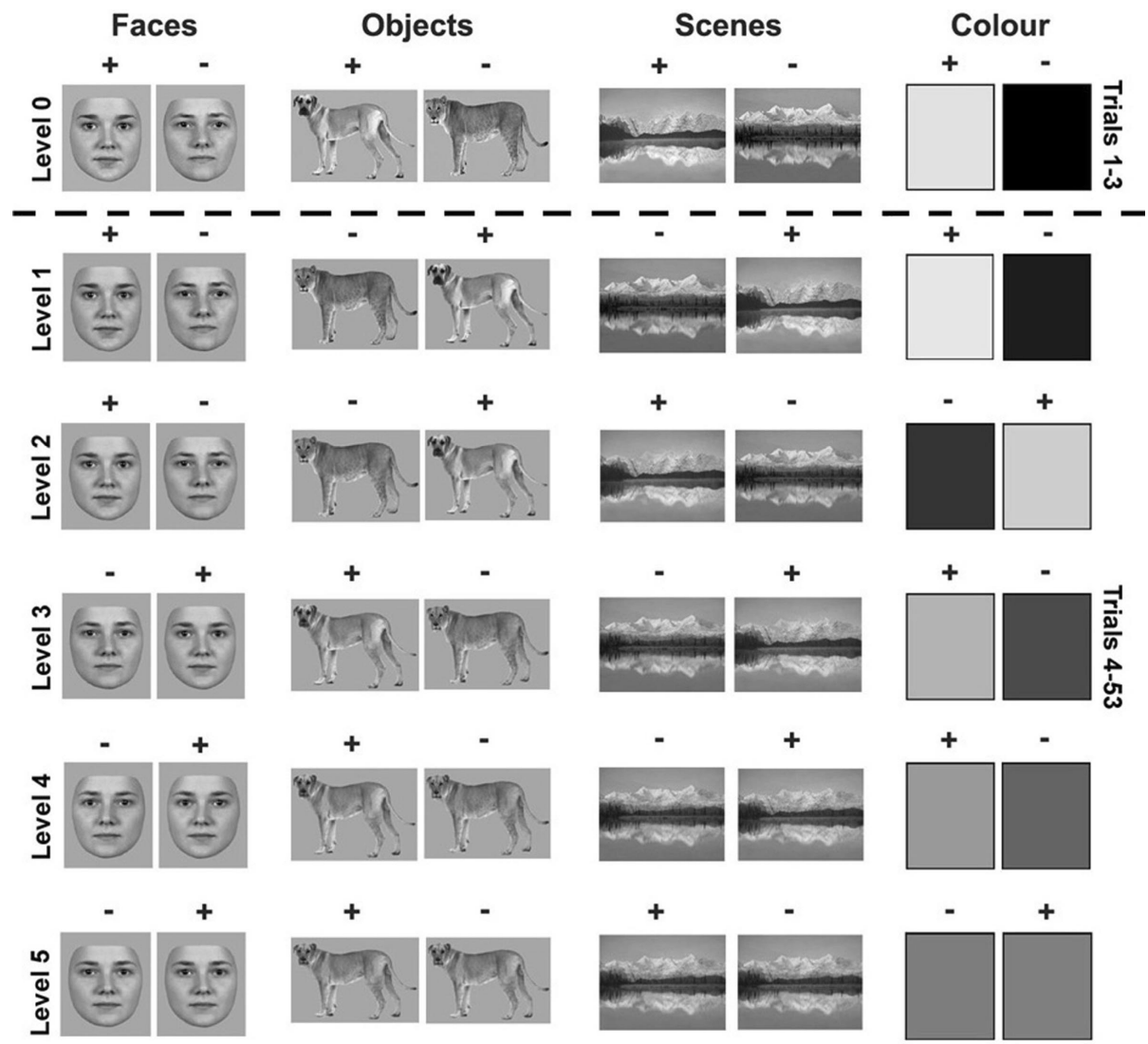

Figure 1. One trial from each level of feature overlap from the discrimination performance task used in Lee et al. (2005c). (+) indicates correct stimulus; $(-)$ indicates incorrect stimulus. The simultaneous matching task was identical, but on each trial the original correct stimulus (i.e., Level 0) was displayed above the two choice stimuli. 
correct stimulus, and auditory feedback was provided for all trials. Thus, this first task required the participants to hold onto the representation of the original correct picture throughout the 50 trials of each condition, and it assessed different difficulties of fine visual discrimination as the two test stimuli on each trial shared varying levels of features.

In the second simultaneous matching task (administered a few months later), the identical paradigm was used but with one critical difference: On each trial the original correct stimulus was always shown above the two choice stimuli. Thus, there was a minimal mnemonic component in this task, and successful performance was not dependent on the participants having to remember the original correct stimulus throughout the duration of each task condition.

In support of the idea that the human hippocampus and perirhinal cortex may be critical to scene and object perception, respectively, it was found that on both the discrimination performance and simultaneous matching tasks, the two patient groups were impaired in the discrimination of spatial scenes, while the MTL group patients demonstrated an additional impairment in discriminating faces and, to a lesser extent, objects (there was a significant MTL group impairment on the discrimination performance, but not on the simultaneous matching, object condition). In contrast, neither patient group had any difficulties discriminating colour. Given the similar findings across the two task versions, and the fact that the simultaneous matching task had a reduced mnemonic component, it is likely that the observed deficits were not mnemonic in nature, but rather reflected difficulties in scene (HC and MTL group) and object, including face (MTL group only), perception (Lee et al., 2005c).

While this recent study was a significant first demonstration of perceptual deficits in patients with MTL damage, there were, however, a number of alternative explanations for these findings that were not inconsistent with the view that the human MTL subserves mnemonic processes exclusively. First, the patient deficits observed in Lee et al. (2005c) may have been due to a learning effect that was only present in the controls and resulted in an improvement in their performance across blocks. While the simultaneous matching task did not require the participants to hold onto a representation of the original correct stimulus, all 50 trials within each condition were created by blending the same stimulus pair to varying degrees. Thus, it is possible that the control group could have benefited from subtle learning due to the repetition of components of the stimuli across trials. To undermine this explanation, however, analyses of task performance across the blocks of each task condition revealed that none of the subject groups showed a significant effect of learning in the two versions of the discrimination paradigm and, moreover, that the significant differences between the patient groups and the controls were not restricted to the later blocks of trials on the scenes and faces conditions. In addition to this, the control groups made an increasing number of errors across trial blocks for certain stimuli, indicating that any learning was inhibiting, rather than benefiting, task performance.

A second possible explanation for the findings of Lee et al. (2005c) is that the perceptual deficits observed in the HC and MTL patient groups could have been the result of additional atrophy to cortical areas beyond the hippocampus and perirhinal cortex that are known to be involved in higher visual processing: for instance, lateral temporal lobe regions, including area TE/TEO. One line of evidence against this idea, however, is the structural ratings of the MRI scans of the patients. These ratings, based on a scale validated against volumetric methods (Galton et al., 2001), revealed that the hippocampal patients did not 
have any cortical damage beyond the hippocampus, suggesting that any perceptual impairment in this group was likely to be the result of this selective damage. Similarly, whereas the MTL patients had larger lesions that encompassed the hippocampus and surrounding regions (including the perirhinal cortex, amygdala, and anterior temporal lobe), the majority of these patients did not have significant damage to lateral temporal lobe regions. In addition to this, both HC and MTL patients performed within the normal range when making difficult colour discriminations, an ability that has been previously shown to be dependent upon area TE/TEO in nonhuman primates (Buckley, Gaffan, \& Murray, 1997).

\section{Deficits in oddity judgement following human MTL damage}

In an attempt to replicate the findings of Lee et al. (2005c) and to reconcile the findings of this study with that of Stark and Squire (2000), Lee et al. (2005a) assessed oddity judgement in the same amnesic patients that were assessed in Lee et al. (2005c). Versions of the original oddity tasks that were used in perirhinal lesioned monkeys (Buckley et al., 2001) were administered, as well as a number of new oddity tests to assess spatial perception (see Figure 2):

1. Reassessment of Stark and Squire (2000). To investigate the findings of Stark and Squire (2000), oddity judgement for colour, faces, and objects was investigated. As in this previous study, participants were required to select the odd stimulus from an array of six images. In our experiment, however, the stimulus set sizes of the faces and objects were significantly

a

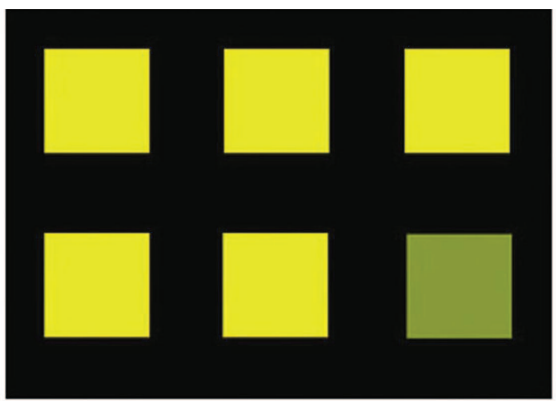

C

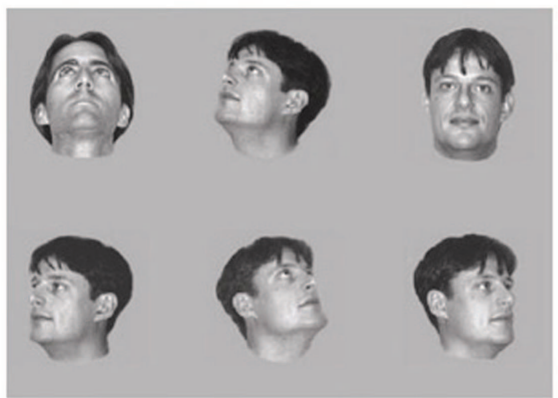

b

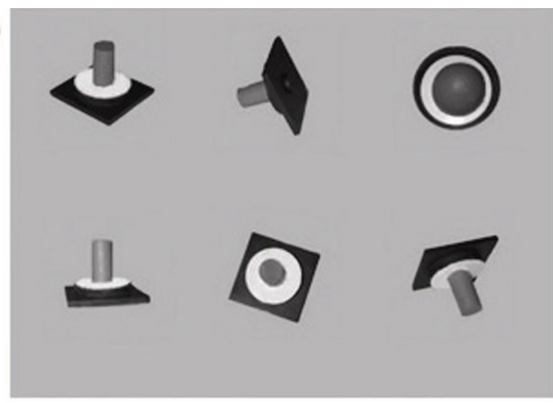

d

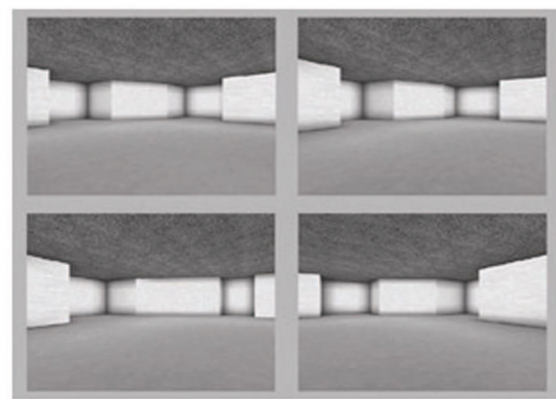

Figure 2. One trial from the (a) colour; (b) object; (c) face; and (d) scene oddity tasks used in Lee et al. (2005a). 
increased (sets of 20 items were used, in comparison to 10 in Stark \& Squire, 2000). This change was made since studies in monkeys have shown that large set sizes may be required to observe visual concurrent discrimination deficits following perirhinal cortex lesions (Buckley \& Gaffan, 1997; although see Hampton, this issue), presumably by increasing feature "overlap" across trials.

2. Assessing spatial perception and the possible role of learning. To investigate whether spatial perception deficits could be observed in the context of an oddity paradigm, we administered a test that assessed oddity judgement for virtual reality rooms. On any given trial, patients were presented with four images on the screen and were required to select the odd stimulus. Three of these scenes were different vantage points of the same virtual reality room, while one was a fourth view of a different room that differed slightly in the arrangement and/or size of certain aspects (e.g., wall, pillar, or room cavity). Thus, in order to solve this task, the participants had to use a complete three-dimensional representation of the rooms within each trial. It is important to note that in order to rule out possible effects of learning, trial-unique stimuli were used, with no room being shown more than once in each condition.

Consistent with recent suggestions that the hippocampus is involved in space, and not object, perception, the HC group was significantly impaired on oddity judgements for virtual reality rooms, but not for faces, objects, or colour. The MTL patients were also impaired on the virtual reality rooms task, but additionally demonstrated significant impairments when they were required to make oddity judgements for faces as well as objects. They were, however, not significantly impaired in the colour condition. Thus, the profile of performance observed by Lee et al. (2005a) in the MTL patients contradicted the findings of Stark and Squire (2000), who found, using similar tasks, that patients with MTL damage were not significantly impaired on oddity judgements for faces or objects. It is highly possible that the increase in stimulus set size in Lee et al., 2005a, contributed to this difference.

The finding of deficits in both the HC and MTL groups in the scenes task further supports the idea that the human hippocampus may be critical to spatial perception and, furthermore, is consistent with the myriad of evidence demonstrating deficits in spatial memory following hippocampal damage (Bohbot et al., 2004; Bohbot et al., 1998; Burgess et al., 2002; Feigenbaum \& Morris, 2004; King et al., 2002; King et al., 2004; Spiers et al., 2001b). Interestingly, recent studies have reported impaired allocentric, but not egocentric, memory for spatial scenes in patients with selective hippocampal lesions (Bohbot et al., 2004; Feigenbaum \& Morris, 2004; Holdstock et al., 2000b; King et al., 2002; King et al., 2004). In general, patients with hippocampal damage are comparable to healthy control subjects or only mildly impaired at recognizing object locations that are viewed from the same viewpoint as that during the learning phase (i.e., intact egocentric memory). These patients are, however, severely impaired when object locations are viewed from a different viewpoint from that at learning (i.e., impaired allocentric memory; Feigenbaum \& Morris, 2004; King et al., 2002; King et al., 2004). It is possible that these findings may also map onto the perceptual domain, with hippocampal damage causing difficulties in scene perception when the layout of a scene has to be processed from multiple vantage points as demonstrated by Lee et al. (2005a). In support of this possibility, recent data have suggested that patients with hippocampal lesions are able to make oddity judgements for scenes when these discriminations can be solved on the basis of egocentric processing. The amnesic patients from Lee et al. (2005a) were presented with three identical images of the same room taken from 
the same viewpoint with a fourth image of a separate room from a different view. It was found that irrespective of the location of their cortical damage (i.e., selective hippocampal damage versus larger MTL lesions) all the patients were able to select successfully the odd stimulus (Lee et al., 2005a).

\section{Convergence of findings in visual discrimination and oddity judgement}

The consistent findings of perceptual deficits in two separate paradigms (Lee et al., 2005a; Lee et al., 2005c), as well as their convergence with data from the nonhuman primate literature (e.g., Buckley et al., 2001; Bussey et al., 2002; Bussey et al., 2003), have provided the strongest evidence to date that the human MTL may play a critical role in higher order perception (see Figure 3), with the hippocampus and perirhinal cortex involved in spatial and object perception, respectively. The fact that the amnesic patients in these studies performed within the normal range on general tests of perception (e.g., the copying condition of the Rey-Osterrieth figure, Osterrieth, 1944, and the VOSP, Warrington \& James, 1991) highlights again the fact that these tests do not place an adequate demand on the perceptual processes that the human MTL have been proposed to subserve. For example, making a copy of the Rey-Osterrieth figure with pen and paper can be done on a feature-by-feature basis, while many of the tests of the VOSP (e.g., the counting of dots and letter identification) do not involve complex object or spatial scene perception, which are dependent on processing conjunctions of features. Perceptual deficits following MTL damage may, therefore, only be evident when tasks that cannot be solved on the basis of single visual features (i.e., that place a demand on the perception of multiple features within objects and scenes) are employed.

(a)

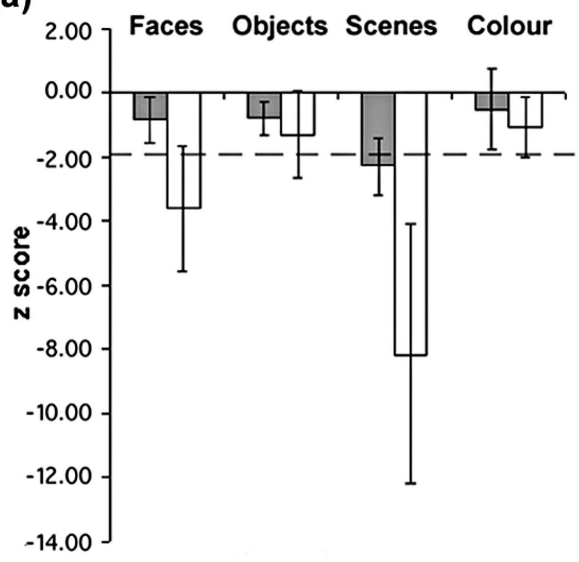

(b)

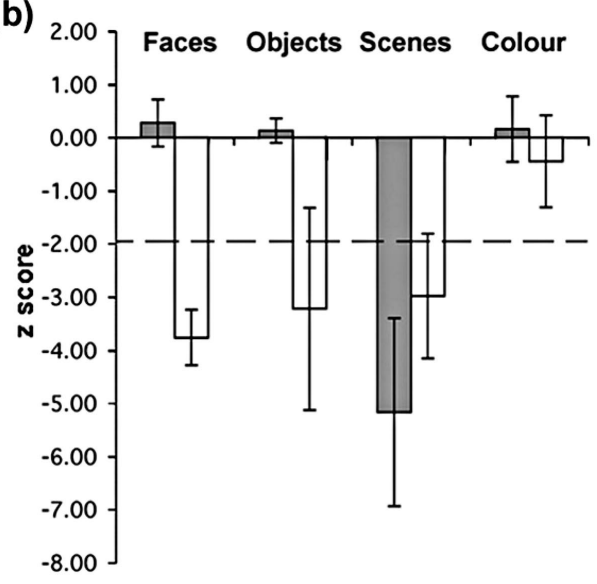

$\square$ पC $\square$ MTL

Figure 3. $\mathrm{Z}$ score plots for the two patient groups when compared to matched controls on different conditions of (a) simultaneous matching (Lee et al., 2005c) and (b) oddity judgement (Lee et al., 2005a). Scores beyond the dashed line $(z=-1.96)$ indicate significant impairment. 


\section{Perceptual deficits as a cause of amnesia?}

Given the recent evidence for perceptual deficits in humans following MTL damage (Lee et al., 2005a; Lee et al., 2005c), it is important to consider how perceptual and mnemonic deficits may interact with each other. One controversial proposal stemming primarily from the animal literature proposes that the perceptual deficits documented following MTL damage may, in fact, be the underlying cause of the memory deficits seen after such injury (Gaffan, 2001; Horel, 1978; O’Keefe, 1999). When considering the existing neuropsychological literature, however, it is difficult to conceive that the human amnesic syndrome may result primarily from perceptual deficits. For instance, impairments in spatial perception in patients with selective hippocampal damage (Lee et al., 2005a; Lee et al., 2005c) cannot account easily for difficulties in mnemonic tasks that do not, at least overtly, contain a spatial component. These include remembering studied pairs of words (e.g., Giovanello, Verfaellie, \& Keane, 2003 ) as well as recalling a previously presented prose passage after a delay.

It is important to note that although these types of task do not place an explicit demand on processing spatial information, it is possible, nevertheless, that spatial perception may still be essential to task performance. One argument is that spatial memory may be spontaneously recruited during the encoding and retrieval of an experienced episode (Gaffan, 2001). For instance, the accuracy of recalling an event in life may benefit from the reconstruction of the entire event, a critical part of which may be the spatial context in which the event took place. Subsequently, an impairment in spatial processing may impede this process and produce difficulties in mnemonic processing (Gaffan, 2001).

Although further research is required to understand a possible interaction between space perception and mnemonic impairments in human amnesics, the impact of object perception difficulties on learning has been investigated recently by Barense et al. (2005). In brief, the amnesic patients seen previously in Lee et al. (2005a, 2005c) were assessed on a visual concurrent discrimination task that was based on a paradigm previously shown to be dependent upon the perirhinal cortex in monkeys (Bussey et al., 2002). The participants were required to learn to discriminate between pairs of objects that possessed varying degrees of overlapping features (a property of visual discrimination termed "feature ambiguity"). Two of the conditions involved "blobs" and "bugs", and each stimulus item was composed of two explicitly defined features, or components (e.g., shape and fill; see Figure 4). For each stimulus type, three levels of perceptual discrimination were used: minimum, intermediate, and maximum feature ambiguity. Each of these levels involved four objects (two correct targets and two incorrect nontargets) presented in pairs (one target randomly paired with one nontarget), and the number of trials that the participants needed to learn the target items was assessed. In the minimum feature ambiguity level, no object features were ambiguous (i.e., both features were unique to target and nontarget objects). In contrast, in the intermediate feature ambiguity level, half of the features were ambiguous (i.e., one feature appeared in both a target and a nontarget, but the other feature was unique to the target), whereas in the maximum feature ambiguity level, all features were ambiguous (i.e., both features of the target also appeared separately in nontargets). Successful discriminations in the maximum condition required the participants to learn the conjunction of the two features that correctly distinguished targets from nontargets (e.g., dot fill and six-pronged shape), and they could not be solved using a single feature (e.g., dot fill) since no individual 


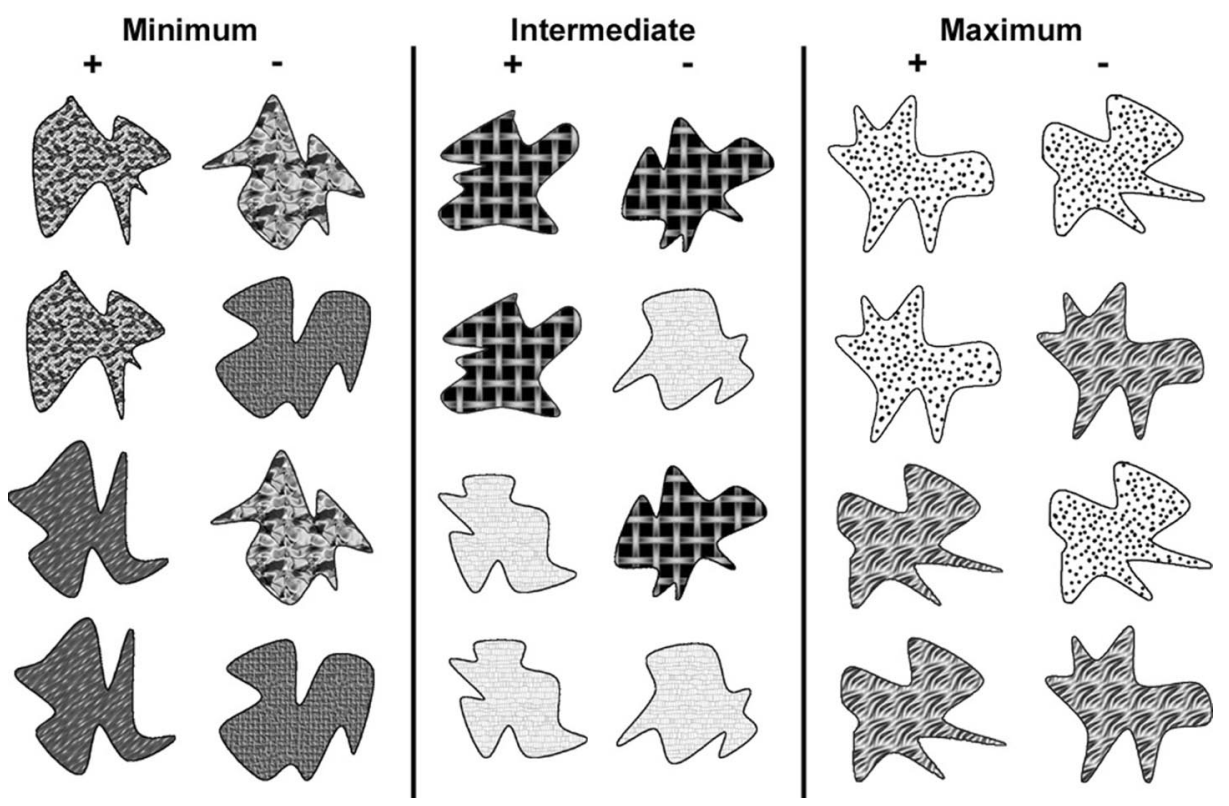

Figure 4. Minimum, intermediate, and maximum feature ambiguity levels for the "blobs" condition in Barense et al. (2005). (+) indicates correct stimulus; $(-)$ indicates incorrect stimulus. The two manipulated feature components were shape and fill and the position of the target on the screen was counter balanced.

features were unique to the targets. Importantly, the number of objects to be remembered was constant for all conditions, but as feature ambiguity was increased, the demand on learning feature conjunctions was increased parametrically.

Contrary to the idea that all MTL structures function as a single mnemonic system, Barense et al. (2005) found that the patients with selective hippocampal lesions (HC group) performed within the normal range on all conditions of the blobs and bugs tasks, thus demonstrating an intact ability to learn object discriminations (i.e., they required a similar number of trials as did healthy control subjects to learn all discriminations). In contrast, whereas the patients with larger MTL lesions (MTL group) generally performed normally on all minimum feature ambiguity conditions, they were significantly impaired on the intermediate and maximum feature ambiguity levels (i.e., when a greater demand was placed on discriminating conjunctions of features, they required a significantly greater number of trials than did healthy control subjects to learn the discrimination). Given that healthy control subjects performed equally across all conditions, it is unlikely that the deficits observed in the MTL group were due to task difficulty. Moreover, although there were an equal number of stimuli in each condition, a greater number of features were presented in the minimum (eight features) than in the maximum ambiguity (four features) levels. Thus, the magnitude of impairment in the MTL group was inversely related to the number of features presented. This suggests that the number of items to be discriminated and any differences in memory load were not critical to eliciting impairments in MTL patients. 
The findings of Barense et al. (2005) highlight two important points about memory and the human MTL. First, the hippocampus does not appear to be critical for all forms of declarative learning. This supports the idea of functional fractionation within the MTL and that different structures within the MTL may subserve different aspects of memory processing (e.g., Aggleton \& Brown, 1999; Brown \& Aggleton, 2001; Mishkin et al., 1997). Second, it is possible that changes in perceptual demand can influence mnemonic function. More specifically, the ability to encode and retrieve long-term memories may be affected by the perceptual properties of the stimuli involved. This implies that when interpreting behavioural performance on a mnemonic task, it is critical that the class (scene or object) and featural composition (minimal vs. maximal ambiguity) of the stimuli employed are considered, in addition to the mnemonic demands of the test. It is important to note, however, that while the findings of Barense et al. (2005) suggest that perceptual deficits can lead to impairments in memory, it is still unclear to what extent amnesia can be accounted for in terms of difficulties in object, or even space, perception.

\section{Reconciling perceptual and mnemonic theories of MTL function}

The suggestion that perceptual deficits can influence mnemonic performance in amnesic cases with focal MTL damage (Barense et al., 2005) raises the question as to how perceptual theories of MTL function can be reconciled with existing ideas of the role of MTL structures in mnemonic processes. One likelihood is that perceptual and mnemonic theories of MTL function are not mutually exclusive. For instance, considering the perirhinal cortex, it is conceivable that different populations of neurons within this region mediate familiaritybased recognition memory and object perception. It is known from nonhuman primate electrophysiological studies that there are perirhinal neurons that decrease their firing in response to subsequent presentations of unfamiliar objects (Brown, Wilson, \& Riches, 1987; Li, Miller, \& Desimone, 1993; Sobotka \& Ringo, 1993), and it has been suggested that this mechanism may constitute the neural basis of recognition memory (for review see Brown \& Xiang, 1998). There are also, however, neurons that possess stimulus specificity but do not exhibit decremental response patterns (Xiang \& Brown, 1998), and, moreover, studies have shown that recognition memory can be dissociated from the decremental response properties of some perirhinal neurons (Sobotka \& Ringo, 1996). Thus, it is possible that there may be a variety of neural mechanisms that make separate contributions to the mnemonic and perceptual processes that the perirhinal cortex has been suggested to subserve.

With regard to the hippocampus, the idea that this region may be critical for spatial perception concurs with the existing theory that this structure may function as a spatial module or cognitive map (O'Keefe \& Nadel, 1978). It is possible that hippocampal cells that signal aspects of spatial location are important to this role (Ekstrom et al., 2003; Hori et al., 2003; O'Keefe, 1976; O’Keefe \& Burgess, 1996; O'Keefe et al., 1998; Ono et al., 1991; Ono, Nakamura, Nishijo, \& Eifuku, 1993; Wilson \& McNaughton, 1993), although it is still unclear as to whether this same mechanism may contribute to declarative memory encoding and retrieval processes.

A possible role for the hippocampus in spatial, but not object, perception is also not necessarily contradictory to a relational memory view of the hippocampus (i.e., that this 
structure is involved in the memory for relationships among perceptually distinct items; Cohen et al., 1999; Eichenbaum \& Cohen, 2002; Eichenbaum et al., 1994) providing that the hippocampus is believed to mediate the association of relations among elements of scenes or events and not the binding of features of individual objects. Thus, while patients with selective hippocampal lesions are able to discriminate objects that possess overlapping features, they have difficulties when they have to perceive the multiple relations between these objects: for example, in the context of a spatial scene.

\section{Future directions}

If the human MTL is involved in higher order perceptual processes, then one would expect the perceptual deficits seen in amnesics with static lesions to be replicable in other patient populations with MTL pathology. Two ideal candidates for this are Alzheimer's Disease (AD), a condition that is characterized by a primary deficit in episodic memory and at least one other significant impairment in a different cognitive domain, such as attention, working memory and language (Grady et al., 1988; Hodges \& Patterson, 1995; McKahnn et al., 1984; Perry \& Hodges, 1996, 1999; Welsh, Butters, Hughes, Mohs, \& Heyman, 1992), and semantic dementia (SD), a neurodegenerative disease that is associated with a progressive, crossmodal loss of semantic knowledge, with relative preservation in other cognitive domains (Garrard, Perry, \& Hodges, 1997; Hodges \& Patterson, 1995; Hodges, Patterson, Oxbury, \& Funnell, 1992; Perry \& Hodges, 1996; Snowden, Goulding, \& Neary, 1989; Snowden, Neary, \& Mann, 1996; Warrington, 1975). Recent volumetric studies have shown differing profiles of atrophy to MTL regions in these two diseases (Chan et al., 2001; Davies, Graham, Xuereb, Williams, \& Hodges, 2004; Davies, Xuereb, \& Hodges, 2002; Galton et al., 2001), with predominant involvement of the perirhinal cortex in SD compared to other MTL regions, and primary atrophy throughout the hippocampus in AD (Davies, Graham, Xuereb, Williams \& Hodges, 2004, although see Bright Moss, Stamatakis, \& Tyler, this issue). Consistent with perceptual theories of the MTL, preliminary data have suggested that perceptual deficits may, in fact, also be present in patients with these disorders, with AD patients demonstrating impairments in scene discrimination and SD patients showing deficits in discriminating faces (Lee et al., 2005b).

Another important issue for investigation is defining the role that the hippocampus may play in spatial perception. As discussed earlier, existing studies of spatial memory suggest that the hippocampus may be important for allocentric processes. Recent nonhuman primate work has found, however, that hippocampal dysfunction, by means of fornix transection, can result in deficits in learning conjunctions of spatial information: for instance, the association between tail length, orientation, and spatial location of tadpoles within a two-dimensional scene (Buckley et al., 2004). Similarly, our own investigations suggest that amnesic patients with hippocampal damage have difficulties discriminating images of scenes that share a high proportion of overlapping features but do not necessarily place a demand on allocentric processing (Lee et al., 2005c). Thus, it is currently unclear how perceiving conjunctions of spatial information relates to allocentric processes and what role the hippocampus may play in each of these. In addition to this, given that the parahippocampal gyrus is also likely to play an important role in spatial memory (Bohbot et al., 2004; Bohbot et al., 1998; Ekstrom et al., 2003) as well as the encoding of perceptual information about the layout of scenes 
(Epstein, Harris, Stanley, \& Kanwisher, 1999), further research will be necessary to determine the distinct contributions made by the parahippocampal gyrus and hippocampus to spatial perception.

\section{Summary}

Contrary to traditional views, there is now evidence emerging to suggest that the human MTL may mediate the same nonmnemonic processes that have been proposed for the animal MTL, with the hippocampus and perirhinal cortex subserving aspects of spatial and object perception, respectively. If true, perceptual theories of human MTL function will have a profound impact on the way in which human amnesia is understood, in particular whether deficits in perception are related to impairments in mnemonic processes.

\section{REFERENCES}

Aggleton, J. P., \& Brown, M. W. (1999). Episodic memory, amnesia and the hippocampal-anterior thalamic axis. Behavioral and Brain Sciences, 22, 425-289.

Alvarez, P., Zola-Morgan, S., \& Squire, L. R. (1994). The animal model of human amnesia: Long-term memory impaired and short-term memory intact. Proceedings of the National Academy of Sciences USA, 91, 5637-5641.

Baddeley, A., Vargha-Khadem, F., \& Mishkin, M. (2001). Preserved recognition in a case of developmental amnesia: Implications for the acquisition of semantic memory? Fournal of Cognitive Neuroscience, 13, 357-369.

Barense, M. D., Bussey, T. J., Lee, A. C. H., Rogers, T. T., Davies, R. R., Saksida, L. M., et al. (2005). Functional specialization in the human medial temporal lobe. Manuscript submitted for publication.

Bayley, P. J., \& Squire, L. R. (2004). Failure to acquire new semantic knowledge in patients with large medial temporal lobe lesions. Hippocampus, 15, 273-280.

Beatty, W. W., Salmon, D. P., Bernstein, N., \& Butters, N. (1987). Remote memory in a patient with amnesia due to hypoxia. Psychological Medicine, 17, 657-665.

Bennett, G. K., Seashore, H. G., \& Wesman, A. G. (1972). Differential aptitude test manual (5th ed.). New York: Psychological Corporation.

Benson, D. F., Marsden, C. D., \& Meadows, J. C. (1974). The amnesic syndrome of posterior cerebral artery occlusion. Acta Neurologica Scandinavica, 50, 133-145.

Benton, A. L., Hamsher, K., Varney, N. R., \& Spreen, O. (1983). Fudgement of line orientation: Contributions to neuropsychological assessment. New York: Oxford University Press.

Benton, A. L., \& Van Allen, M. W. (1968). Impairment in facial recognition in patients with cerebral disease. Cortex, 4, 344-358.

Benzing, W. C., \& Squire, L. R. (1989). Preserved learning and memory in amnesia: Intact adaptation-level effects and learning of stereoscopic depth. Behavioral Neuroscience, 103, 538-547.

Bohbot, V. D., Iaria, G., \& Petrides, M. (2004). Hippocampal function and spatial memory: Evidence from functional neuroimaging in healthy participants and performance of patients with medial temporal lobe resections. Neuropsychology, 18, 418-425.

Bohbot, V. D., Kalina, M., Stepankova, K., Spackova, N., Petrides, M., \& Nadel, L. (1998). Spatial memory deficits in patients with lesions to the right hippocampus and to the right parahippocampal cortex. Neuropsychologia, 36, 1217-1238.

Bright, P., Moss, H. E., Stamatakis, E. A., \& Tyler, L. K. (this issue). The anatomy of object processing: The role of anteromedial temporal cortex. Quarterly Journal of Experimental Psychology, 58B, 361-377.

Brown, M. W., \& Aggleton, J. P. (2001). Recognition memory: What are the roles of the perirhinal cortex and hippocampus? Nature Reviems Neuroscience, 2, 51-61.

Brown, M. W., Wilson, F. A., \& Riches, I. P. (1987). Neuronal evidence that inferomedial temporal cortex is more important than hippocampus in certain processes underlying recognition memory. Brain Research, 409, $158-162$. 
Brown, M. W., \& Xiang, J. Z. (1998). Recognition memory: Neuronal substrates of the judgement of prior occurrence. Progress in Neurobiology, 55, 149-189.

Buckley, M. J. (this issue). The role of the perirhinal cortex and hippocampus in learning, memory, and perception. Quarterly Journal of Experimental Psychology, 58B, 246-268.

Buckley, M. J., Booth, M. C., Rolls, E. T., \& Gaffan, D. (2001). Selective perceptual impairments after perirhinal cortex ablation. Fournal of Neuroscience, 21, 9824-9836.

Buckley, M. J., Charles, D. P., Browning, P. G., \& Gaffan, D. (2004). Learning and retrieval of concurrently presented spatial discrimination tasks: Role of the fornix. Behavioral Neuroscience, 118, 138-149.

Buckley, M. J., \& Gaffan, D. (1997). Learning and transfer of object-reward associations and the role of the perirhinal cortex. Behavioral Neuroscience, 112, 1-9.

Buckley, M. J., Gaffan, D., \& Murray, E. A. (1997). Functional double dissociation between two inferior temporal cortical areas: Perirhinal cortex versus middle temporal gyrus. Fournal of Neurophysiology, 77, 587-598.

Buffalo, E. A., Reber, P. J., \& Squire, L. R. (1998). The human perirhinal cortex and recognition memory. Hippocampus, 8, 330-339.

Burgess, N., Maguire, E. A., \& O'Keefe, J. (2002). The human hippocampus and spatial and episodic memory. Neuron, 35, 625-641.

Bussey, T. J., \& Saksida, L. M. (2002). The organization of visual object representations: A connectionist model of effects of lesions in perirhinal cortex. European Fournal of Neuroscience, 15, 355-364.

Bussey, T. J., Saksida, L. M., \& Murray, E. A. (2002). Perirhinal cortex resolves feature ambiguity in complex visual discriminations. European Fournal of Neuroscience, 15, 365-374.

Bussey, T. J., Saksida, L. M., \& Murray, E. A. (2003). Impairments in visual discrimination after perirhinal cortex lesions: Testing 'declarative' vs. 'perceptual-mnemonic' views of perirhinal cortex function. European fournal of Neuroscience, 17, 649-660.

Bussey, T. J., Saksida, L. M., \& Murray, E. A. (this issue). The perceptual-mnemonic/feature conjunction model of perirhinal cortex function. Quarterly Journal of Experimental Psychology, 58B, 269-282.

Cave, C. B., \& Squire, L. R. (1992a). Intact and long-lasting repetition priming in amnesia. Fournal of Experimental Psychology: Learning, Memory, and Cognition, 18, 509-520.

Cave, C. B., \& Squire, L. R. (1992b). Intact verbal and nonverbal short-term memory following damage to the human hippocampus. Hippocampus, 2, 151-163.

Chan, D., Fox, N. C., Scahill, R. I., Crum, W. R., Whitwell, J. L., Leschziner, G., et al. (2001). Patterns of temporal lobe atrophy in semantic dementia and Alzheimer's disease. Annals of Neurology, 49, 433-442.

Chun, M. M., \& Phelps, E. A. (1999). Memory deficits for implicit contextual information in amnesic subjects with hippocampal damage. Nature Neuroscience, 2, 844-847.

Cipolotti, L., Shallice, T., Chan, D., Fox, N., Scahill, R., Harrison, G., et al. (2001). Long-term retrograde amnesia...the crucial role of the hippocampus. Neuropsychologia, 39, 151-172.

Cohen, N. J., Ryan, J., Hunt, C., Romine, L., Wszalek, T., \& Nash, C. (1999). Hippocampal system and declarative (relational) memory: Summarizing the data from functional neuroimaging studies. Hippocampus, 9, 83-98.

Cummings, J. L., Tomiyasu, U., Read, S., \& Benson, D. F. (1984). Amnesia with hippocampal lesions after cardiopulmonary arrest. Neurology, 34, 679-687.

Davies, R. R., Graham, K. S., Xuereb, J. H., Williams, G. B., \& Hodges, J. R. (2004). The human perirhinal cortex and semantic memory. European Fournal of Neuroscience, 20, 2441-2446.

Davies, R. R., Xuereb, J. H., \& Hodges, J. R. (2002). The human perirhinal cortex in semantic memory: An in vivo and postmortem volumetric magnetic resonance imaging study in semantic dementia, Alzheimer's disease and matched controls. Neuropathology and Applied Neurobiology, 28, 167-168.

Dejong, R. N., Itabashi, H. H., \& Olson, J. R. (1969). Memory loss due to hippocampal lesions. Archives of Neurology, 20, 339-348.

Duyckaerts, C., Derouesne, C., Signoret, J. L., Gray, F., Escourolle, R., \& Castaigne, P. (1985). Bilateral and limited amygdalohippocampal lesions causing a pure amnesic syndrome. Annals of Neurology, 18, 314-319.

Eacott, M. J., Gaffan, D., \& Murray, E. A. (1994). Preserved recognition memory for small sets, and impaired stimulus identification for large sets, following rhinal cortex ablations in monkeys. European fournal of Neuroscience, 6, 1466-1478.

Eichenbaum, H., \& Cohen, N. J. (2002). From conditioning to conscious recollection: Memory systems of the brain. Oxford, UK: Oxford University. 
Eichenbaum, H., Otto, T., \& Cohen, N. J. (1994). Two functional components of the hippocampal memory system. Behavioral and Brain Science, 17, 449-518.

Ekstrom, A. D., Kahana, M. J., Caplan, J. B., Fields, T. A., Isham, E. A., Newman, E. L., et al. (2003). Cellular networks underlying human spatial navigation. Nature, 425, 184-188.

Epstein, R., Harris, A., Stanley, D., \& Kanwisher, N. (1999). The parahippocampal place area: Recognition, navigation, or encoding? Neuron, 23, 115-125.

Eslinger, P. (1998). Autobiographical memory after temporal lobe lesions. Neurocase, 4, 481-495.

Feigenbaum, J. D., \& Morris, R. G. (2004). Allocentric versus egocentric spatial memory after unilateral temporal lobectomy in humans. Neuropsychology, 18, 462-472.

Fujii, T., Yamadori, A., Endo, K., Suzuki, K., \& Fukatsu, R. (1999). Disproportionate retrograde amnesia in a patient with herpes simplex encephalitis. Cortex, 35, 599-614.

Gabrieli, J. D., Cohen, N. J., \& Corkin, S. (1988). The impaired learning of semantic knowledge following bilateral medial temporal-lobe resection. Brain and Cognition, 7, 157-177.

Gabrieli, J. D., Corkin, S., Mickel, S. F., \& Growdon, J. H. (1993). Intact acquisition and long-term retention of mirror-tracing skill in Alzheimer's disease and in global amnesia. Behavioral Neuroscience, 107, 899-910.

Gadian, D. G., Aicardi, J., Watkins, K. E., Porter, D. A., Mishkin, M., \& Vargha-Khadem, F. (2000). Developmental amnesia associated with early hypoxic-ischaemic injury. Brain, 123, (3), 499-507.

Gaffan, D. (2001). What is a memory system? Horel's critique revisited. Behavioral Brain Research, 127, 5-11.

Gaffan, D., Parker, A., \& Easton, A. (2001). Dense amnesia in the monkey after transection of fornix, amygdala and anterior temporal stem. Neuropsychologia, 39, 51-70.

Gage, P. (1985). Preserved and impaired information processing in human bitemporal amnesiacs and their intrahuman analogues. Fournal of Mind and Behaviour, 6, 515-551.

Galton, C. J., Gomez-Anson, B., Antoun, N., Scheltens, P., Patterson, K., Graves, M., et al. (2001). Temporal lobe rating scale: Application to Alzheimer's disease and frontotemporal dementia. Fournal of Neurology, Neurosurgery, and Psychiatry, 70, 165-173.

Galton, C. J., Patterson, K., Graham, K., Lambon-Ralph, M. A., Williams, G., Antoun, N., et al. (2001). Differing patterns of temporal atrophy in Alzheimer's disease and semantic dementia. Neurology, 57, 216-225.

Garrard, P., Perry, R., \& Hodges, J. R. (1997). Disorders of semantic memory. Fournal of Neurology, Neurosurgery, and Psychiatry, 62, 431-435.

Giovanello, K. S., Verfaellie, M., \& Keane, M. M. (2003). Disproportionate deficit in associative recognition relative to item recognition in global amnesia. Cognitive, Affective and Behavioral Neuroscience, 3, 186-194.

Gollin, E. S. (1960). Developmental studies of visual recognition of incomplete objects. Perceptual and Motor Skills, $11,289-298$.

Gottschaldt, K. (1929). Über den Einfluss der Erfahrung auf die Wahrnehmung von Figuren. Psychologische Forschung, 12, 1-87.

Grady, C. L., Haxby, J. V., Horwitz, B., Sundaram, M., Berg, G., Schapiro, M., et al. (1988). Longitudinal study of the early neuropsychological and cerebral metabolic changes in dementia of the Alzheimer type. Fournal of Clinical and Experimental Neuropsychology, 10, 576-596.

Hampton, R. R. (this issue). Monkey perirhinal cortex is critical for visual memory, but not for visual perception: Re-examination of the behavioural evidence from monkeys. Quarterly Fournal of Experimental Psychology, 58B, 283-299.

Hampton, R. R., Hampstead, B. M., \& Murray, E. A. (2004). Selective hippocampal damage in rhesus monkeys impairs spatial memory in an open-field test. Hippocampus, 14, 808-818.

Henke, K., Kroll, N. E., Behniea, H., Amaral, D. G., Miller, M. B., Rafal, R., et al. (1999). Memory lost and regained following bilateral hippocampal damage. Fournal of Cognitive Neuroscience, 11, 682-697.

Henson, R. (this issue). A mini-review of FMRI studies of human medical temporal lobe activity associated with recognition memory. Quarterly Fournal of Experimental Psychology, 58B, 340-360.

Hodges, J. R., \& Patterson, K. (1995). Is semantic memory consistently impaired early in the course of Alzheimer's disease? Neuroanatomical and diagnostic implications. Neuropsychologia, 33, 441-459.

Hodges, J. R., Patterson, K., Oxbury, S., \& Funnell, E. (1992). Semantic dementia. Progressive fluent aphasia with temporal lobe atrophy. Brain, 115 (6), 1783-1806.

Holdstock, J. S. (this issue). The role of the human medial temporal lobe in object recognition and object discrimination. Quarterly Fournal of Experimental Psychology, 58B, 326-339. 
Holdstock, J. S., Gutnikov, S. A., Gaffan, D., \& Mayes, A. R. (2000a). Perceptual and mnemonic matching-to-sample in humans: Contributions of the hippocampus, perirhinal and other medial temporal lobe cortices. Cortex, 36, 301-322.

Holdstock, J. S., Mayes, A. R., Cezayirli, E., Isaac, C. L., Aggleton, J. P., \& Roberts, N. (2000b). A comparison of egocentric and allocentric spatial memory in a patient with selective hippocampal damage. Neuropsychologia, 38 , $410-425$.

Holdstock, J. S., Mayes, A. R., Roberts, N., Cezayirli, E., Isaac, C. L., O'Reilly, R. C., et al. (2002). Under what conditions is recognition spared relative to recall after selective hippocampal damage in humans? Hippocampus, $12,341-351$.

Horel, J. A. (1978). The neuroanatomy of amnesia. A critique of the hippocampal memory hypothesis. Brain, 101, $403-445$.

Hori, E., Tabuchi, E., Matsumura, N., Tamura, R., Eifuku, S., Endo, S., et al. (2003). Representation of place by monkey hippocampal neurons in real and virtual translocation. Hippocampus, 13, 190-196.

Iverson, S. D. (1977). Temporal lobe amnesia. In C. W. M. Whitty \& O. L. Zangwill (Eds.), Amnesia (pp. 136-182). Boston: Butterworths.

Kapur, N., Ellison, D., Parkin, A. J., Hunkin, N. M., Burrows, E., Sampson, S. A., et al. (1994). Bilateral temporal lobe pathology with sparing of medial temporal lobe structures: Lesion profile and pattern of memory disorder. Neuropsychologia, 32, 23-38.

Kartsounis, L. D., Rudge, P., \& Stevens, J. M. (1995). Bilateral lesions of CA1 and CA2 fields of the hippocampus are sufficient to cause a severe amnesic syndrome in humans. Fournal of Neurology, Neurosurgery, and Psychiatry, 59, 95-98.

King, J. A., Burgess, N., Hartley, T., Vargha-Khadem, F., \& O’Keefe, J. (2002). Human hippocampus and viewpoint dependence in spatial memory. Hippocampus, 12, 811-820.

King, J. A., Trinkler, I., Hartley, T., Vargha-Khadem, F., \& Burgess, N. (2004). The hippocampal role in spatial memory and the familiarity-recollection distinction: A case study. Neuropsychology, 18, 405-417.

Kitchener, E. G., Hodges, J. R., \& McCarthy, R. (1998). Acquisition of post-morbid vocabulary and semantic facts in the absence of episodic memory. Brain, 121 (7), 1313-1327.

Lee, A. C. H., Buckley, M. J., Pegman, S. J., Spiers, H., Scahill, V. L., Gaffan, D., et al. (2005a). Specialisation in the medial temporal lobe for processing of objects and scenes. Manuscript submitted for publication.

Lee, A. C. H., Bussey, T. J., Murray, E. A., Levi, N., Saksida, L. M., Davies, R. R., et al. (2005b). Object and scene memory in semantic dementia and Alzheimer's Disease: A double dissociation. Manuscript in preparation.

Lee, A. C., Bussey, T. J., Murray, E. A., Saksida, L. M., Epstein, R. A., Kapur, N., et al. (2005c). Perceptual deficits in amnesia: Challenging the medial temporal lobe 'mnemonic' view. Neuropsychologia, 43, 1-11.

Levy, D. A., Stark, C. E., \& Squire, L. R. (2004). Intact conceptual priming in the absence of declarative memory. Psychology Science, 15, 680-686.

Li, L., Miller, E. K., \& Desimone, R. (1993). The representation of stimulus familiarity in anterior inferior temporal cortex. Fournal of Neurophysiology, 69, 1918-1929.

Manns, J. R., Hopkins, R. O., Reed, J. M., Kitchener, E. G., \& Squire, L. R. (2003a). Recognition memory and the human hippocampus. Neuron, 37, 171-180.

Manns, J. R., Hopkins, R. O., \& Squire, L. R. (2003b). Semantic memory and the human hippocampus. Neuron, $38,127-133$.

Manns, J. R., \& Squire, L. R. (2001). Perceptual learning, awareness, and the hippocampus. Hippocampus, 11, $776-782$.

Mayes, A. R., Holdstock, J. S., Isaac, C. L., Hunkin, N. M., \& Roberts, N. (2002). Relative sparing of item recognition memory in a patient with adult-onset damage limited to the hippocampus. Hippocampus, 12, $325-340$.

Mayes, A. R., Holdstock, J. S., Isaac, C. L., Montaldi, D., Grigor, J., Gummer, A., et al. (2004). Associative recognition in a patient with selective hippocampal lesions and relatively normal item recognition. Hippocampus, 14, $763-784$.

McKahnn, G., Drachman, D., Folstein, M., Katzman, R., Price, D., \& Stadlan, E. M. (1984). Clinical diagnosis of Alzheimer's disease: Report of the NINCDS-ADRDA Work Group under the auspices of Department of Health and Human Services Task Force on Alzheimer's Disease. Neurology, 34, 939-944.

Milner, B., Corkin, S., \& Teuber, H.-L. (1968). Further analysis of the hippocampal amnesic syndrome: 14-year follow-up of HM. Neuropsychologia, 6, 215-234. 
Mishkin, M. (1982). A memory system in the monkey. Philosophical Transactions of the Royal Society of London. Series B: Biological Sciences, 298, 83-95.

Mishkin, M., Suzuki, W. A., Gadian, D. G., \& Vargha-Khadem, F. (1997). Hierarchical organization of cognitive memory. Philosphical Transactions of the Royal Society of London. Series B: Biological Sciences, 352, 1461-1467.

Muramoto, O., Kuru, Y., Sugishita, M., \& Toyokura, Y. (1979). Pure memory loss with hippocampal lesions: A pneumoencephalographic study. Archives of Neurology, 36, 54-56.

Murray, E. A., \& Bussey, T. J. (1999). Perceptual-mnemonic functions of the perirhinal cortex. Trends in Cognitive Sciences, 3, 142-151.

Murray, E. A., Davidson, M., Gaffan, D., Olton, D. S., \& Suomi, S. (1989). Effects of fornix transection and cingulate cortical ablation on spatial memory in rhesus monkeys. Experimental Brain Research, 74, 173-186.

Musen, G., \& Squire, L. R. (1992). Nonverbal priming in amnesia. Memory E Cognition, 20, 441-448.

O'Keefe, J. (1976). Place units in the hippocampus of the freely moving rat. Experimental Neurology, 51, 78-109.

O'Keefe, J. (1999). Do hippocampal pyramidal cells signal non-spatial as well as spatial information? Hippocampus, 9, 352-364.

O'Keefe, J., \& Burgess, N. (1996). Geometric determinants of the place fields of hippocampal neurons. Nature, 381, $425-428$.

O’Keefe, J., Burgess, N., Donnett, J. G., Jeffery, K. J., \& Maguire, E. A. (1998). Place cells, navigational accuracy, and the human hippocampus. Philosophical Transactions of the Royal Society of London. Series B: Biological Sciences, 353, 1333-1340.

O'Keefe, J., \& Nadel, L. (1978). The hippocampus as a cognitive map. Oxford, UK: Clarendon Press.

Ono, T., Nakamura, K., Fukuda, M., \& Tamura, R. (1991). Place recognition responses of neurons in monkey hippocampus. Neuroscience, Letters, 121, 194-198.

Ono, T., Nakamura, K., Nishijo, H., \& Eifuku, S. (1993). Monkey hippocampal neurons related to spatial and nonspatial functions. Fournal of Neurophysiology, 70, 1516-1529.

Osterrieth, P. A. (1944). Le test de copie d'une figure complexe. Archives de Psychologie, 30, 205-220.

Oxbury, S., Oxbury, J., Renowden, S., Squier, W., \& Carpenter, K. (1997). Severe amnesia: An usual late complication after temporal lobectomy. Neuropsychologia, 35, 975-988.

Perry, R. J., \& Hodges, J. R. (1996). Spectrum of memory dysfunction in degenerative disease. Current Opinion in Neurology, 9, 281-285.

Perry, R. J., \& Hodges, J. R. (1999). Attention and executive deficits in Alzheimer's disease. A critical review. Brain, $122(3), 383-404$.

Postle, B. R., \& Corkin, S. (1998). Impaired word-stem completion priming but intact perceptual identification priming with novel words: Evidence from the amnesic patient H.M. Neuropsychologia, 36, 421-440.

Ratcliff, G. (1979). Spatial thought, mental rotation and the right cerebral hemisphere. Neuropsychologia, 17, 49-54.

Rempel-Clower, N. L., Zola, S. M., Squire, L. R., \& Amaral, D. G. (1996). Three cases of enduring memory impairment after bilateral damage limited to the hippocampal formation. Fournal of Neuroscience, 16, 5233-5255.

Scoville, W. B., \& Milner, B. (1957). Loss of recent memory after bilateral hippocampal lesions. Fournal of Neurochemistry, 20, 11-21.

Sidman, M., Stoddard, L. T., \& Mohr, J. P. (1968). Some additional quantitative observations of immediate memory. Neuropsychologia, 6, 245-254.

Snowden, J., Goulding, P., \& Neary, D. (1989). Semantic dementia: A form of circumscribed cerebral atrophy. Behavioural Neurology, 2, 167-182.

Snowden, J., Neary, D., \& Mann, D. (1996). Frontotemporal lobar degeneration: Frontotemporal dementia, progressive aphasia, semantic dementia. London: Churchill Livingstone.

Sobotka, S., \& Ringo, J. L. (1993). Investigation of long-term recognition and association memory in unit responses from inferotemporal cortex. Experimental Brain Research, 96, 28-38.

Sobotka, S., \& Ringo, J. L. (1996). Mnemonic responses of single units recorded from monkey inferotemporal cortex, accessed via transcommissural versus direct pathways: A dissociation between unit activity and behavior. Fournal of Neuroscience, 16, 4222-4230.

Spiers, H. J., Burgess, N., Hartley, T., Vargha-Khadem, F., \& O'Keefe, J. (2001b). Bilateral hippocampal pathology impairs topographical and episodic memory but not visual pattern matching. Hippocampus, 11, 715-725.

Spiers, H. J., Maguire, E. A., \& Burgess, N. (2001a). Hippocampal amnesia. Neurocase, 7, 357-382.

Squire, L. R. (1993). Cross-modal matching performance in amnesia. Neuropsychology, 7, 375-384. 
Squire, L. R. (2004). Memory systems of the brain: a brief history and current perspective. Neurobiology Learning and Memory, 82, 171-177.

Squire, L. R., Stark, C. E., \& Clark, R. E. (2004). The medial temporal lobe. Annual Reviem of Neuroscience, 27, 279-306.

Squire, L., \& Zola-Morgan, S. (1991). The medial temporal lobe memory system. Science, 253, 1380-1386.

Stark, C. E., \& Squire, L. R. (2000). Intact visual perceptual discrimination in humans in the absence of perirhinal cortex. Learning E Memory 7, 273-278.

Starr, A., \& Phillips, L. (1970). Verbal and motor learning in the amnestic syndrome. Neuropsychologia, 8, $75-88$.

Vargha-Khadem, F., Gadian, D. G., Watkins, K. E., Connelly, A., Van Paesschen, W., \& Mishkin, M. (1997) Differential effects of early hippocampal pathology on episodic and semantic memory. Science, 277, 376-380.

Von Cramon, D. Y., \& Schuri, U. (1992). The septo-hippocampal pathways and their relevance to human memory: A case report. Cortex, 28, 411-422.

Warrington, E. K. (1975). The selective impairment of semantic memory. Quarterly Fournal of Experimental Psychology, 27, 635-657.

Warrington, E. K., \& James, M. (1991). The Visual Object and Space Perception battery. Bury St. Edmunds, UK: Thames Valley Test Company.

Welsh, K. A., Butters, N., Hughes, J. P., Mohs, R. C., \& Heyman, A. (1992). Detection and staging of dementia in Alzheimer's disease. Use of the neuropsychological measures developed for the Consortium to Establish a Registry for Alzheimer's Disease. Archives of Neurology, 49, 448-452.

Wilson, M. A., \& McNaughton, B. L. (1993). Dynamics of the hippocampal ensemble code for space. Science, 261, 1055-1058.

Woods, B. T., Schoene, W., \& Kneisley, L. (1982). Are hippocampal lesions sufficient to cause lasting amnesia? Journal of Neurology, Neurosurgery, and Psychiatry, 45, 243-247.

Xiang, J. Z., \& Brown, M. W. (1998). Differential neuronal encoding of novelty, familiarity and recency in regions of the anterior temporal lobe. Neuropharmacology, 37, 657-676.

Yonelinas, A. P., Kroll, N. E., Quamme, J. R., Lazzara, M. M., Sauve, M. J., Widaman, K. F., et al. (2002). Effects of extensive temporal lobe damage or mild hypoxia on recollection and familiarity. Nature Neuroscience, 5, 1236-1241.

Zola-Morgan, S., Squire, L. R., \& Amaral, D. G. (1986). Human amnesia and the medial temporal region: Enduring memory impairment following a bilateral lesion limited to field CA1 of the hippocampus. Fournal of Neuroscience, 6, 2950-2967.

Zola-Morgan, S., Squire, L. R., \& Ramus, S. J. (1994). Severity of memory impairment in monkeys as a function of locus and extent of damage within the medial temporal lobe memory system. Hippocampus, 5, 232-239. 